\title{
Quantitative Estimation of the Ratio of GABA-Immunoreactive Cells in Neocortical Grafts
}

\author{
A. Bragin*, J. Takăcs**, O. Vinogradova* and J. Hámori** \\ * Institute of Biophysics of the USSR Academy of Sciences, Moscow-Puschino, USSR \\ ** 1st Department of Anatomy, Semmelweis Medical University, Budapest, Hungary
}

\begin{abstract}
SUMMARY
Somatosensory anlage from 17-18 day old rat embryos were transplanted in place of the removed barrel cortex in adult rats. Six to eight months after transplantation, the grafts were either completely separated by glial scar or partly separated and partly confluent with the host neocortex. Each was studied histologically and immunostained for GABA. It was found that in partly confluent grafts the neuronal density was similar or even higher than in the host cortex, while the cell number in the separate grafts was much lower than in the nearby host cortex. The number of GABA-positive cells, however, was in all grafts significantly lower (2.9\% on average) than in the normal cortex (11.8\% on average). The decline in GABAstained nerve cells was highest in separated grafts, but was somewhat less marked in transplants partly confluent with the host tissue. The possible role of partial or total deafferentation as well as the relative vulnerability of the transplanted tissue by temporary hypoxia and other metabolic disturbances are discussed as the probable factors in selective decline of GABA-ergic cells in the transplanted somatosensory cortex.
\end{abstract}

\footnotetext{
Reprint address:

J. Takács

1st Department of Anatomy

Semmelweis Medical University

1094 Budapest, Tüzolto u. 58

Hungary
}

\begin{abstract}
Key words: Neocortical transplants; GABAimmunostaining; neuronal numerical density.
\end{abstract}

\section{INTRODUCTION}

It has been shown previously $/ 2,3 /$ that neocortical grafts surviving within the barrel field of the adult rat can be subdivided into two groups. The first group became confluent with the host brain and was only partly separated from the host tissue by glial scar. The second group was completely separated from the host brain by an uninterrupted glial capsule.

These two groups of neocortical grafts also exhibited different electrical activities. The pattern of background activity of the neurons in the first (confluent) group proved to be similar to that of the intact cortical neurons. These neurons responded both to electrical stimulation of the host brain and to sensory stimulation of the animal. In the second group (separated grafts), the background activity consisted of hypersynchronous discharges of many neurons. Spontaneous epileptiform discharges were detectable only in neurons which did not respond to stimulation in the host brain. It was assumed that the appearance of epileptic activity depended on dysfunction of the GABA-ergic system in the graft. The aim of this study was, therefore, to determine the numerical density of GABA-immunoreactive neurons in both separated and confluent cortical grafts. 


\section{MATERIALS AND METHODS}

\section{Grafting}

Wistar rat embryos on the 17-18th gestation day were used as donors. The embryos were decapitated and small (about $2 \times 2 \mathrm{~mm}$ ) pieces of the brain were dissected from the anlage of the somatosensory area. Adult rats of the same strain served as recipients. Under pentobarbital anesthesia (40 mg/kg i.p.) a $5 \times 6 \mathrm{~mm}$ piece was removed from the right side of the skull, and the barrel field was removed by sucking through the opening of the dura. The depth of the cavity was $1-1.5 \mathrm{~mm}$, its width was about $2 \times 4 \mathrm{~mm}$. One solid graft was placed under the incised dura in each recipient. Finally the bone was replaced over the opening of the skull and the skin sutured.

Six to eight months after transplantation the host rats were perfused through the heart (ascending aorta) by $300 \mathrm{ml} 2.5 \%$ paraformaldehyde and $1 \%$ glutaraldehyde (in $0.1 \mathrm{M}$ phosphate buffer, $\mathrm{pH} 7.2$ - 7.4). A piece of the animal's brain - containing the graft and the surrounding neocortex - was removed and cut by tissue chopper in slices of about $500-600 \mu \mathrm{m}$ thick. The slices were stored overnight at $4^{\circ} \mathrm{C}$ in the same fixative, washed several times in phosphate buffer and postosmicated in $1 \% \mathrm{OsO}_{4}$ (in $0.1 \mathrm{M}$ phosphate buffer, $\mathrm{pH} 7.2-7.4$ ) and embedded in Epon.

\section{GABA-immunostaining}

The selection of the proper blocks was made by using toluidine blue stained semithin sections. From these blocks $0.8-1.0 \mu \mathrm{m}$ thick sections were cut and reacted for GABA using antisera as produced and characterized by Hodgson et al. /12/ and applying the post-embedding immunostaining procedure described by Somogyi et al. $120 \%$.

The numerical density of the neurons in the host and in the graft (as well as the packing density of GABA-immunoreactive neurons) was assessed on drawings made of $200 \mu \mathrm{m}$ wide strips of the host cortex and also from the whole graft, using toluidine blue stained semithin sections. Neuronal nuclei (test objects) were outlined at
800 times magnification, and their area as well as the whole investigated area measured. The numerical densities were calculated using the formula of Weibel and Gomez /23/ for ellipsoids:

$$
\mathrm{N}_{\mathrm{v}}=\frac{\mathrm{K}}{\beta} \cdot \frac{\left(\mathrm{N}_{\mathrm{A}}\right)^{3 / 2}}{\left(\mathrm{~V}_{\mathrm{v}}\right)^{1 / 2}}
$$

where $\mathrm{N}_{\mathrm{A}}$ is the number of nuclear profiles per unit area, $V_{v}$ is the volume (or area) fraction, $K$ was chosen as 1.05 and $\beta=1.39$, which is a function of the axial ratios of the ellipsoidal nuclear cross-sections studied.

The grafts (and the host cortices) were analyzed using a Hipad digitising tablet attached to an IBM-PC. In parallel with the GABAimmunostained semithin sections, the GABAimmunoreactive neurons (neuronal nuclei) were outlined and their numerical density calculated similarly to the toluidine blue stained semithin sections. The incidence of GABA-positive neurons was calculated from the two numerical density data.

\section{RESULTS}

Seven rats with surviving grafts were used in this experiment (Table I). The exact position of the grafts within the cortex (i.e., continuous or contiguous with the host tissue) was determined in serial semithin sections. Measurements on the graft-host border revealed that the grafts exhibited different grades of confluence with the host brain. Two grafts (No. 130, 231) were found to be completely separated from the host brain by a continuous glial scar (Fig. 1C). Five other grafts were confluent with the host brain in one or more regions (Fig. 1A,B; Fig. 2A). The length of the confluent and separated "borders" were normalized to 1.0 and their ratio varied from 0.1 to 0.8 .

In GABA-immunoreacted semithin sections some GABA-positive neurons were seen in the separated grafts, while in the host cortex and in the "confluent" grafts the frequency of immunopositive cells was high (Fig. 2B,C). Immunopositive punctuate structures - most probably corresponding to the cross-sections of 

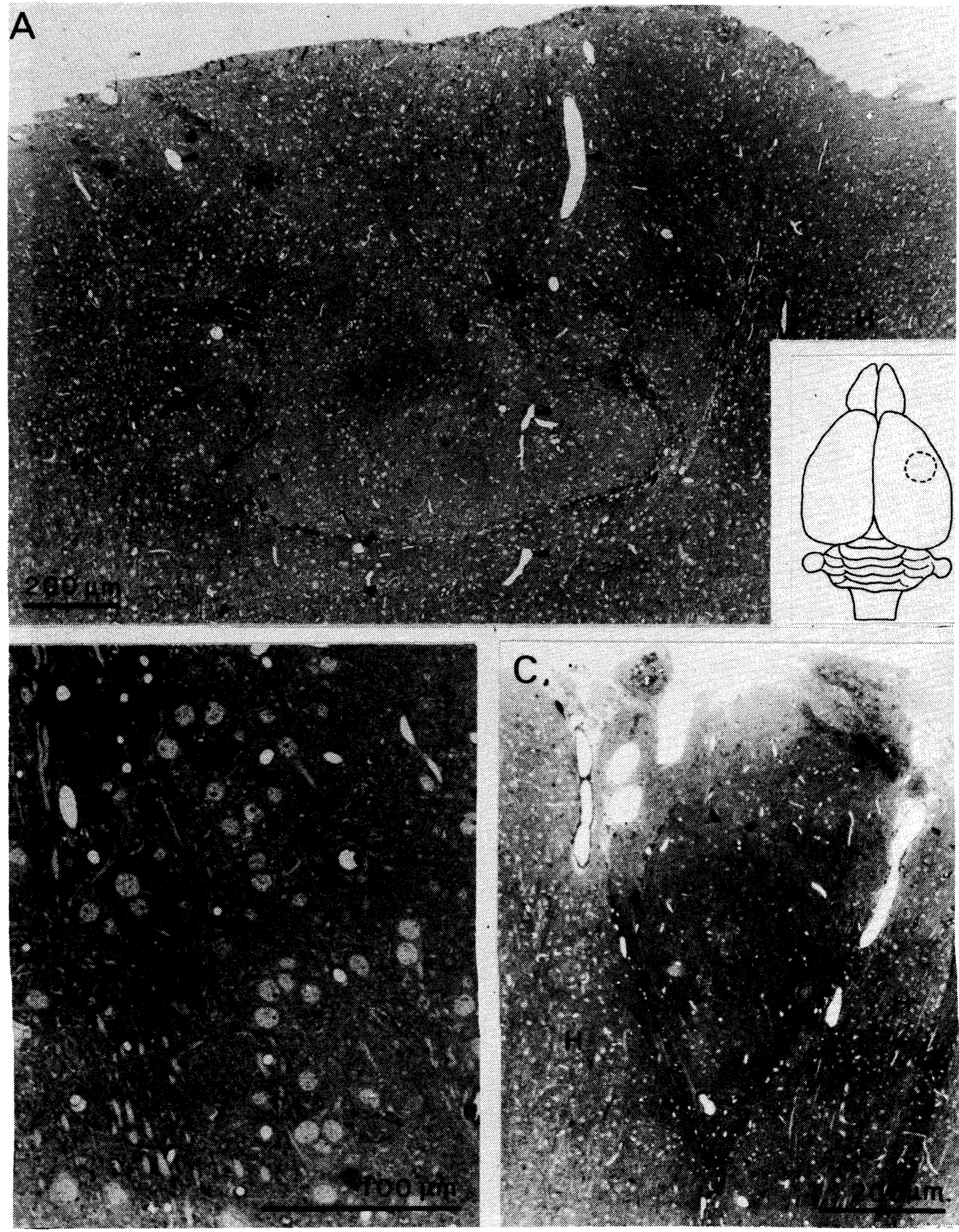

Fig. 1: Cortical transplants six months after grafting somatosensory cortex into adult rats. Toluidine blue stained semithin sections.

A. The transplant $(G)$ is separated in most places from the host cortex $(H)$ by glial scar, but is continuous with the host cortex between arrows. The larger blood vessels are indicated by arrowheads. Insert: schematic drawing of the topographical localization of the graft in the host somatosensory cortex.

B. The continuous part indicated by arrows in Fig $1 \mathrm{~A}$ is shown at higher magnification. G: graft, $\mathrm{H}$ : host. C. A completely separated graft, invaginated into the host cortex. G: graft, H: host. 

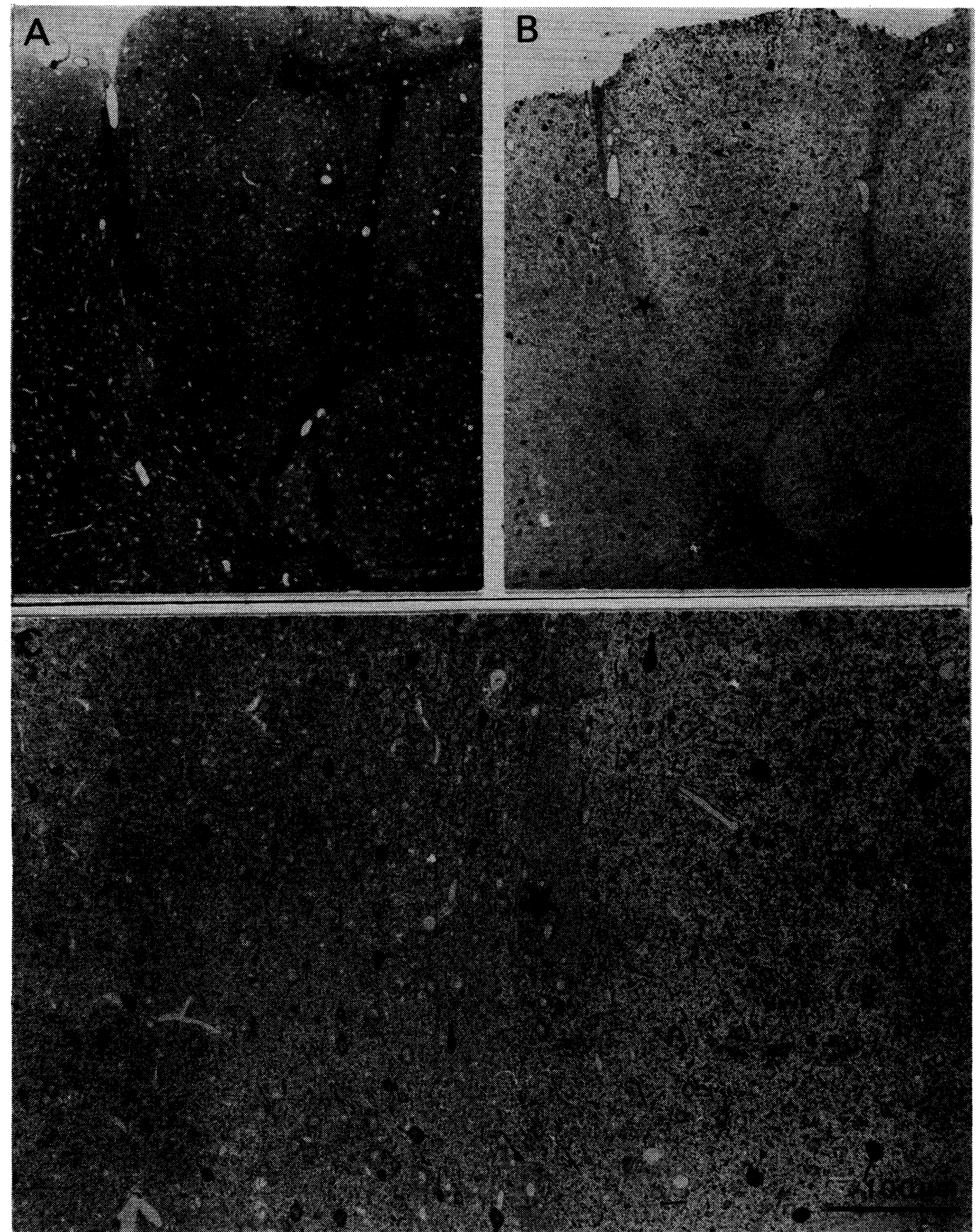

Fig. 2: Partly confluent cortical transplant six months after grafting into the somatosensory cortex of adult rat. A. Toluidine blue stained semithin section: area between arrows shows continuity between the graft $(G)$ and the host $(\mathrm{H})$ cortex.

B. Adjacent section shows GABA-immunopositivity. Area labeled with star is shown with higher magnification in Fig 2C.

C. GABA-Immunopositivity is localized to perikarya as well as to small punctuate structures (boutons). Note that GABA-positive perikarya in the graft $(G)$ are somewhat larger than in the host $(H)$ cortex. 
TABLE I

Numerical density of cortical neurons and density (+ percentage) of GABA-immunoreactive neurons in the host and grafted somatosensory cortex of rat

\begin{tabular}{|c|c|c|c|c|c|c|c|}
\hline \multirow{2}{*}{$\begin{array}{l}\text { Rat } \\
\text { no. }\end{array}$} & \multirow[t]{2}{*}{ Confluency } & \multicolumn{3}{|c|}{ graft } & \multicolumn{3}{|c|}{ host } \\
\hline & & $\begin{array}{c}\mathrm{N}_{\mathrm{V}} \text { (total) } \\
\times 10^{3}\end{array}$ & $\begin{array}{c}\mathrm{N}_{\mathrm{V}} \mathrm{GABA}(+) \\
\times 10^{3}\end{array}$ & $\%$ & $\begin{array}{c}\mathrm{N}_{\mathrm{v}} \text { (total) } \\
\times 10^{3}\end{array}$ & $\begin{array}{c}\mathrm{N}_{\mathrm{v}} \mathrm{GABA}(+) \\
\times 10^{3}\end{array}$ & $\%$ \\
\hline 130 & 0.0 & 18.45 & 0.36 & 1.9 & - & - & - \\
\hline 231 & 0.0 & 27.86 & 0.55 & 2.0 & - & - & - \\
\hline 229 & 0.1 & 39.03 & 1.61 & 4.1 & 40.47 & 5.91 & 14.6 \\
\hline 234 & 0.4 & 45.58 & 2.08 & 4.6 & 48.37 & 6.46 & 13.4 \\
\hline 235 & 0.1 & 34.42 & 0.98 & 2.8 & 43.08 & 3.23 & 7.5 \\
\hline 340 & 0.4 & 63.66 & 1.48 & 2.3 & 35.17 & 4.43 & 12.6 \\
\hline \multirow[t]{3}{*}{358} & 0.8 & 67.02 & 1.56 & 2.3 & 44.14 & 4.86 & 11.0 \\
\hline & & 42.30 & 1.23 & 2.9 & 42.25 & 4.98 & 11.8 \\
\hline & & \pm 17.93 & \pm 0.62 & \pm 1.1 & \pm 4.88 & \pm 1.27 & \pm 2.8 \\
\hline
\end{tabular}

No. of neurons in the neocortex of E17 embryo is $77.31 \times 10^{4} / \mathrm{mm}^{3}$, and $62.54 \times 10^{3} \mathrm{GABA}(+)$ cells $/ \mathrm{mm}^{3}(8.8 \%)$.

dendrites and axon terminals of GABA-positive neurons - were observed in all sections (Fig. 3A). The apical dendrites of grafted cortical pyramidal cells were also surrounded by small dark dots (GABA-positive terminals), particularly in the confluent grafts (Fig. 3B).

The mean area of the GABA-negative neuronal nuclei of the graft was moderately larger $\left(77.4 \pm 20.7 \mu \mathrm{m}^{2}\right)$ than that of the host $\left(57.5 \pm 18.2 \mu \mathrm{m}^{2}\right)$. The average nuclear area of the GABA-positive neurons in the graft (104.0 \pm $26.2 \mu \mathrm{m}^{2}$ ), however, was significantly larger than that of the GABA-ergic neuronal nuclei in the host cortex $\left(71.8 \pm 19.7 \mu \mathrm{m}^{2}\right)$.

The mean numerical density of neurons within the graft $\left(42.30 \pm 17.93 \times 10^{3}\right.$ neurons $/ \mathrm{mm}^{3}$ ) was similar to that of the surrounding host's neocortex $\left(42.25 \pm 4.88 \times 10^{3}\right.$ neurons $/ \mathrm{mm}^{3}$ ). Neuronal density in grafts varied between 18.45 and $67.02 \times 10^{3} / \mathrm{mm}^{3}$ within the graft and between 35.17 and $48.37 \times 10^{3} / \mathrm{mm}^{3}$ in the host neocortex (Table I). The lowest cell density values were found in the completely separated grafts, while in two partially confluent transplants the values were significantly higher than in the host cortex.

The packing density of the GABA-immunoreactive neurons within the host cortex was 4.98 $\pm 1.27 \times 10^{3}$ neurons $/ \mathrm{mm}^{3}$; i.e. $11.8 \%$ of all neurons. In the grafts the packing density of 

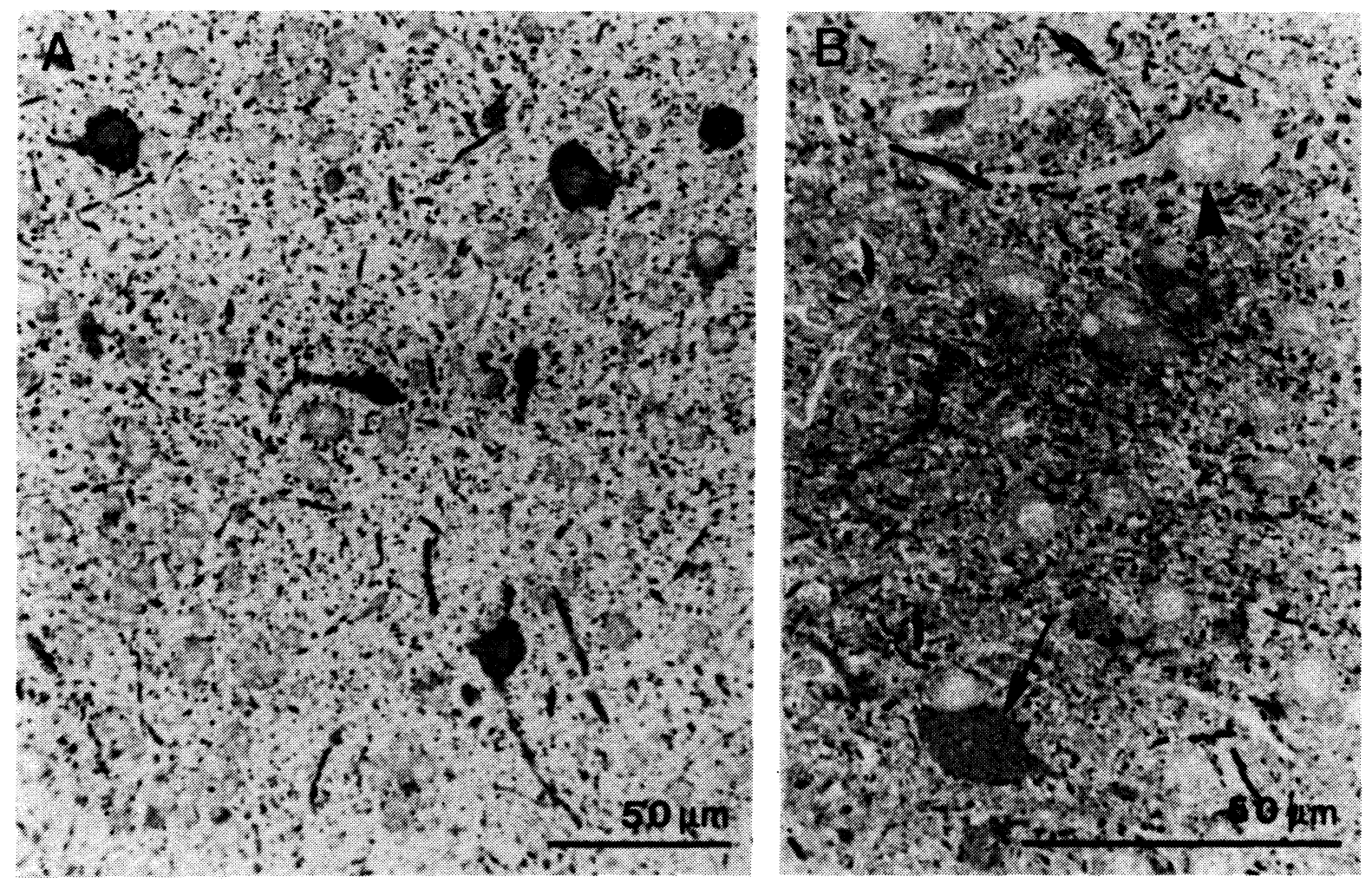

Fig. 3: Higher power of GABA -immunoreactive semithin sections from cortical grafts.

A. GABA-positive perikarya appear somewhat larger than GABA-immunonegative somata.

B. GABA-immunopositive (arrow) as well as immunonegative (arrowhead) cell bodies and apical dendrites are covered by GABA-immunopositive axon terminals.

GABA-positive cells showed considerable individual variation. In the confluent grafts the GABA cell density varied between 0.98 and 2.08 $x 10^{3}$ neurons $/ \mathrm{mm}^{3}$; in the separated grafts, however, the GABA cell numerical density ranged between 0.36 and $0.55 \times 10^{3}$ neurons $/ \mathrm{mm}^{3}$ only.

\section{DISCUSSION}

The morphometric and quantitative estimation of the neurons in the neocortical grafts as compared to the host somatosensory neocortex reveal some remarkable differences.

The mean neuronal nuclear diameter, usually paralleling the size of the neuronal soma, was slightly, but non-significantly, larger in the grafts than in the host somatosensory neocortex. This difference, however, became significant when populations of the GABA-positive cells were compared. The increased size of GABA-positive cells in the graft might be regarded as an indication of delay (or of some disturbance) in their development $/ 16 /$.

In the host somatosensory cortex of the analyzed samples the average numerical density was about $41 \times 10^{3}$ neurons $/ \mathrm{mm}^{3}$. This is about thirty percent less than the value found by Gabbott and Stewart /9/ in the visual cortex of the same species $\left(60 \times 10^{3}\right.$ neurons $\left./ \mathrm{mm}^{3}\right)$. Since, however, the $\mathrm{N}_{\mathrm{v}}$ values for the visual cortex are significantly higher in other mammals $/ 4,7,11,17,22 /$ as compared to other cortical cytoarchitectonic areas, our data apparently represent the true values in the somatosensory cortex of the rat.

It was found that the average numerical density of neurons in the grafts was practically the same as in the host cortex, although a detailed comparison with normal cortex was difficult, since the organotypic layered 
arrangement was usually absent in the grafts. It is well known that the numerical density of the cortical neurons is lowest in the Ist layer, high in the Vth and VIth layers, and maximal in the IInd- IVth layers $/ 8,9 \%$. It appears that neuronal numerical density in the graft depends on the histological characteristics of the embryonic tissue, which may also explain the scattering of $\mathrm{N}_{\mathrm{v}}$ in the various grafts. However, as a general trend, it was recognized that complete separation of the transplant resulted in a more severe cell loss as compared to the partly confluent grafts. In more integrated transplants, the cell density was, in fact, even higher than in the host cortex.

Nevertheless, irrespective of the cellular density in the grafts, the absolute number of GABA-cells is much lower in the transplants than in the host cortex. The mean numerical density of GABA-immunoreactive neurons in the host cortex was $4.98 \times 10^{3}$ neurons $/ \mathrm{mm}^{3}$ (11.8\% of all neurons). This value agrees with that of Gabbott and Stewart /9/, who reported that about $10 \%$ of cortical neurons in the rat visual cortex are non-pyramidal (local inhibitory nerve cells). The average incidence of the GABA-positive neurons in the grafts was only about one fourth $(2.9 \%)$ of that in the host somatosensory cortex.

The significantly lower numerical density of GABA-positive neurons in the grafts cannot be explained by their scanty presence in the initial embryonic material used for grafting. Several groups of investigators have shown that GABApositive neurons migrate and differentiate very early during ontogenesis in the neocortex, dentate fascia and hippocampus $/ 6,13,14,21 /$. Tine generation of GABA-positive cells in the visual and somatosensory neocortex of the rat occurs between days 14 and 18 of embryogenesis (E14-18) $/ 13,15 /$, while many non-GABA-ergic neurons are generated only later. In the present study, embryonic material was taken for grafting on the 17-18th day and, therefore, it was likely that it contained a nearly complete number of GABA-ergic neurons.

Available experimental evidence suggests that GABA-ergic neurons have prominent functional plasticity, and that expression of GABA-markers depends strongly upon the degree of their normal sensory afferentation. A rapid reduction in the intensity of immunostaining for $G A D$ was observed 3 days after peripheral deafferentation in the barrel cortex of adult animals /24/. A decrease of the number of GABAimmunostained neurons in the dominance columns of the primary visual cortex of monkeys was also elicited by simply occluding the corresponding eye /10/. At the same time, functional sensory deprivation resulted in disturbances of the cortical inhibitory processes. Neurons in the cortical barrels deprived of sensory input by destroying the appropriate vibrissae exhibit higher spontaneous activity and reactivity to stimulation of the neighboring vibrissae; their on-off responses are more prolonged, because they are not curtailed by inhibitory postsynaptic potentials /19/. Interestingly, the functional change was not paralleled by any changes of the general cytoarchitectonics of the deprived barrels.

Thus, as one of the possible explanations, it may be suggested that the observed reduction in the number of GABA-immunoreactive neurons in the grafts would be caused by disturbance or by absence of sensory afferentation of the grafted tissue. This assumption seems to be supported by the finding of an extremely low number of GAD-positive neurons in intraocular neocortical grafts completely deprived of extrinsic nervous connections $/ 5 /$.

Another possible explanation for the decline of GABA-positive neuronal density in the grafted cortical tissue may be the relative vulnerability of GABA-ergic neurons to temporary hypoxia /1,18/ or other metabolic damage, which is practically unavoidable during the transplantational procedures. It is also possible that the disturbed or non-existent specific afferentation and the temporary hypoxia would jointly contribute to the decline in the number of GABA cells in transplanted cortical tissue. In either case, it appears that low levels of GABA markers correlate with reduced efficiency of intracortical inhibition. Abnormal epileptiform activity in the isolated cortical and hippocampal grafts were explained in another work by formation of recurrent "autosynapses" between the intergraft neurons, deprived of normal afferent connections and efferent targets 
125/. The present findings indicate that the low number of GABA-ergic elements might directly contribute also to the observed abnormal epileptic activity.

\section{REFERENCES}

1. Auer RN, Siesjo, BK. Biological differences between ischemia, hypoglycemia and epilepsy. Ann Neurol 1988;24:699-707.

2. Bragin AG. The responses of the grafted neocortical neurons into barrel field to vibrissae deflection. Neurophysiology 1986;18:833-836 (in Russian).

3. Bragin AG, Bohne A, Vinogradova OS. Transplants of the embryonal rat somatosensory neocortex in the barrel field of the adult rat: responses of the grafted neurons to sensory stimulation. Neuroscience 1988;25:751-758.

4. Cragg BG. The density of synapses and neurons in the motor and visual areas of the cerebral cortex. J Anat 1967;101:639-654.

5. Eriksdotter-Nilsson NM, Meister B, Hofkelt T. Glutamate decarboxylase and peptide immunoreactive neurons in cortex cerebri following development in isolation: evidence of homtypic and disturbed patterns in intraocular grafts. Synapse 1987;1:539-551.

6. Fairen $\mathrm{A}$, Cobas $\mathrm{A}$, Fonseca $\mathrm{M}$. Times of generation in cortex cerebri mouse somatosensory cortex. J Comp Neurol 1986;251:67-83.

7. Fritschy JM, Garey LJ. Quantitative changes in morphological parameters in the developing visual cortex of the Marmoset monkey. Dev Brain Res 1986;29:173-188.

8. Gabbott PLA, Somogyi P. Quantitative distribution of GABA-immunoreactive neurons in the visual cortex (area 17) of the cat. Exp Brain Res 1987;61:323-331.

9. Gabbott PLA, Stewart MG. Distribution of neurons and glia in the visual cortex (area 17) of the adult albino rat: a quantitative description. Neuroscience 1987;21:833-845.

10. Hendry SHC, Jones EG. Reduction in number of immunostained GABA-ergic neurons in deprived-eye dominance columns of monkey area 17. Nature 1986;320:750-753.

11. Heumann D, Leuba G, Rabinowicz T. Postnatal development of the mouse cerebral neocortex. IV. Evolution of the total cortical volume, of the population of neurons and glial cells. J Hirnforsch 1978;19:385-393.
12. Hodgson AJ, Penke B, Erdei A, Chubb IW, Somogyi P. Antisera to $\gamma$-aminobutyric acid. I. Production and characterization using a new model system. J Histochem Cytochem 1985;33:229-239.

13. Lauder JM, Han VKM, Henderson P, Verdoon T, Towle AC. Prenatal ontogeny of the GABA-ergic system in the rat brain: an immunochemical study. Neuroscience 1986;19:465-493.

14. Lubbers K, Wolf JR, Frotscher M. Neurogenesis of GABA-ergic neurons in the rat dentate gyrus: a combined autoradiographic and immunocytochemical study. Neurosci Lett 1985;62:317-322.

15. Miller $M W$. The migration and neurochemical differentiation of GABA-immunoreactive neurons in rat visual cortex as demonstrated by combined immunocytochemical - autoradiographic technique. Dev Brain Res 1986;28:41-46.

16. Muller LJ, Pattiselano A. Postnatal development of neurons and synapses in the visual cortex of rabbits. In: LJ Muller: Postnatal development of synaptic contacts in the visual cortex of the rabbit. Akademisch Profeschrift. Vrije Univ. Amsterdam, 1983, pp. 35-58.

17. Rockel AJ, Hiorns RW, Powell TPS. The basic uniformity in structure of the neocortex. Brain 1980;103:221-224.

18. Romijn HJ, De Jong BM, Ruijter JM. Hypoxia preferentially destroys GABA-ergic neurons in developing rat neocortex explants in culture. Exp Neurol 1988;100:332-340.

19. Simons DJ, Land PW. Early experience of tactile stimulation influences organization of somatic sensory cortex. Nature 1987;328:694-696.

20. Somogyi P, Hodgson AJ, Chubb IW, Penke B, Erdei A. Antisera to $\boldsymbol{\gamma}$-aminobutyric acid. II. Immunocytochemical application to the central nervous system. J Histochem Cytochem 1985;33:240248.

21. Soriano E, Cobas A, Fairen A. Asynchronism in the neurogenesis of GABA-ergic neurons in the mouse hippocampus. Dev Brain Res 1986;30:88-92.

22. Schuz A, Palm G. Density of neurons and synapses in the cerebral cortex of the mouse. J Comp Neurol 1989;286:442-455.

23. Weibel ER, Gomez DM. A principle for counting tissue structures on random sections. J Appl Physiol 1962;17:343-348.

24. Welker E, Soriano E, Van der Loos H. Plasticity in the barrel cortex of the adult mouse: effect of peripheral deprivation of glutamate decarboxylaseimmunoreactivity. Exp Brain Res 1989;74:441-452.

25. Zhuravleva ZN, Bragin AG, Vinogradova OS. Organization of the nervous tissue (hippocampus and septum) developing in the anterior eye chamber. III. Axonal processes and synaptic ending. J Hirnforschung 1986;27:323-341. 

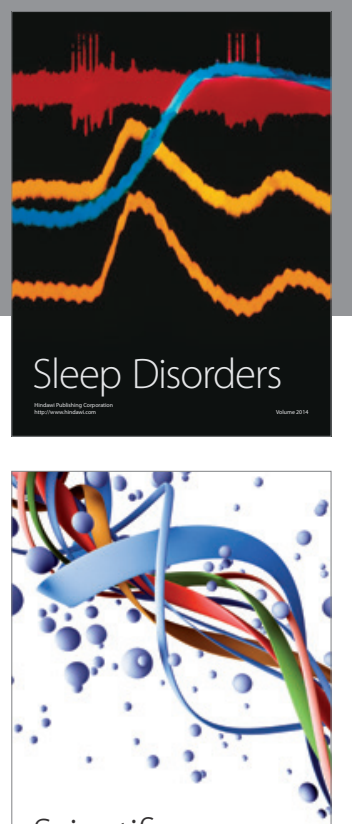

Scientifica
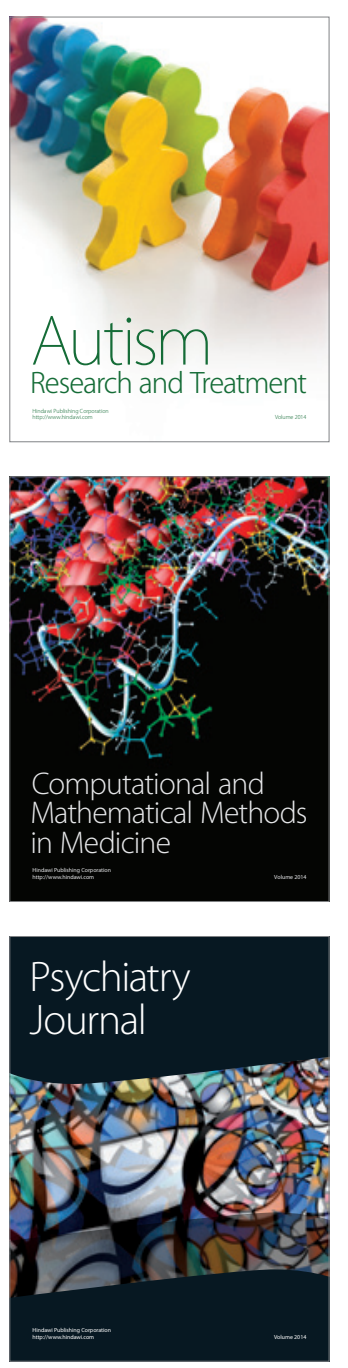
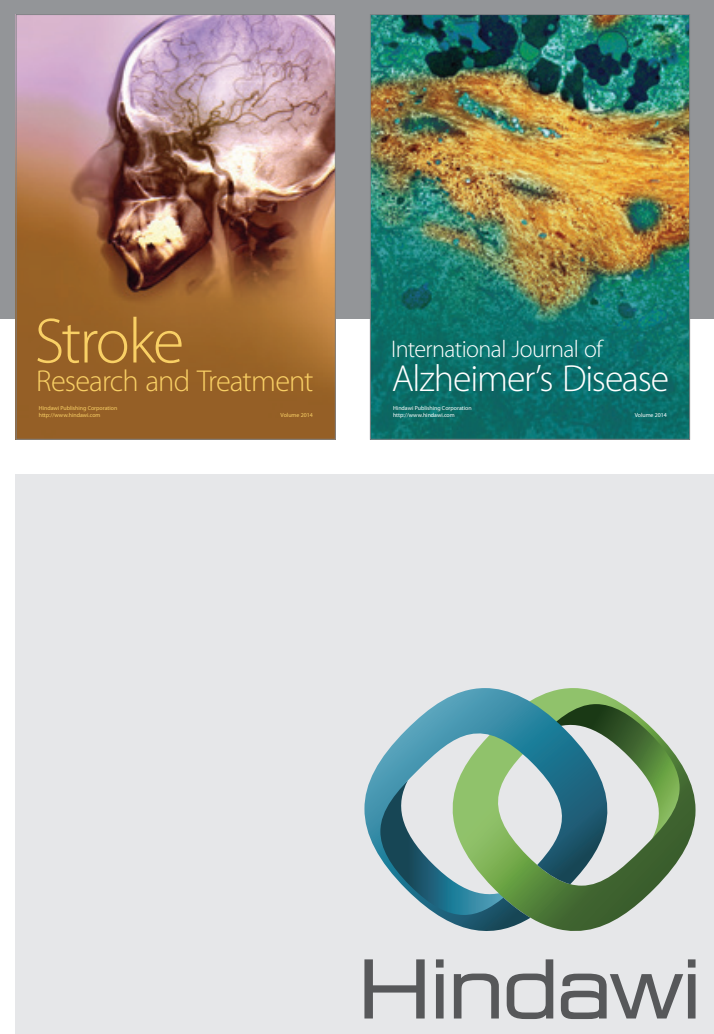

Submit your manuscripts at

http://www.hindawi.com
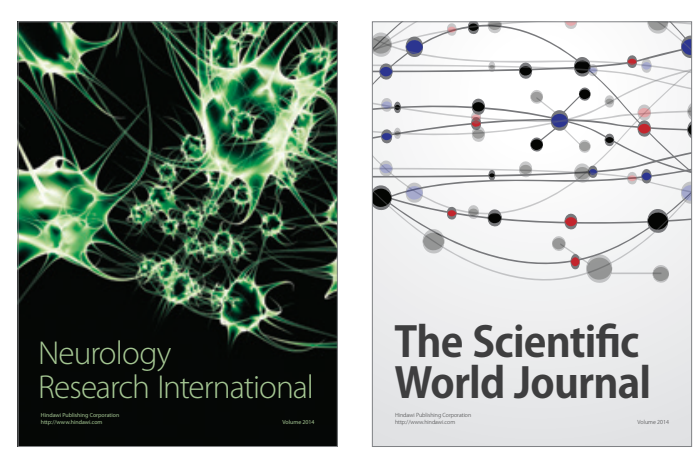

The Scientific World Journal

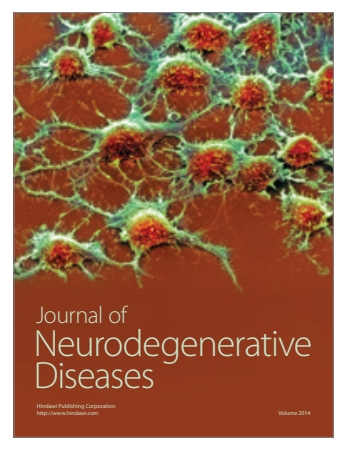

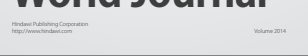

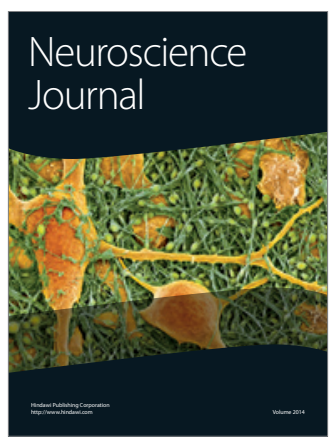

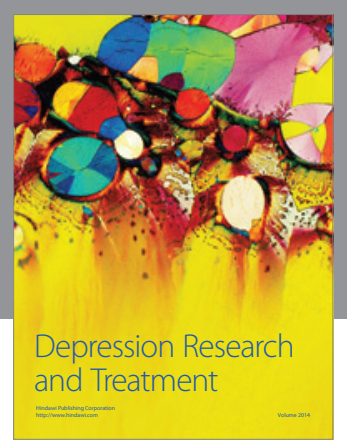
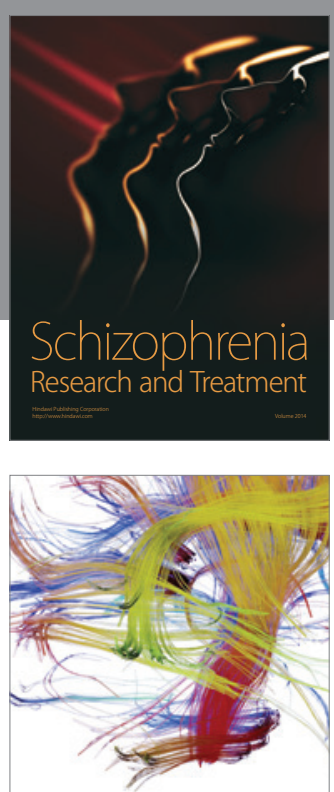

Brain Science

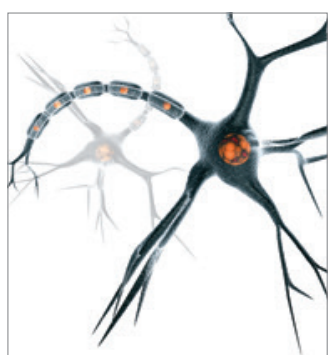

Neural Plasticity
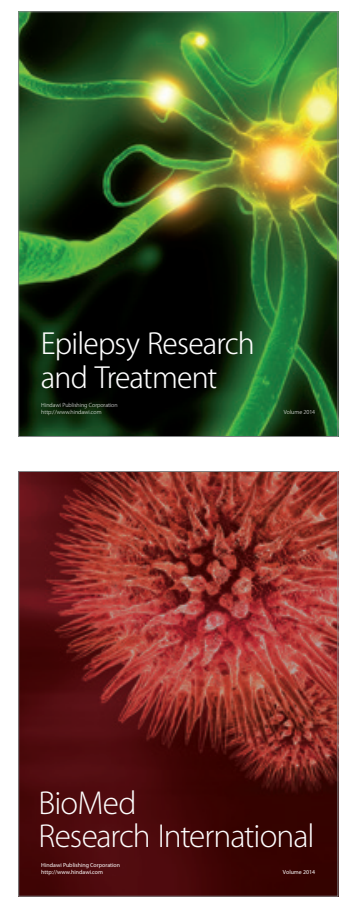

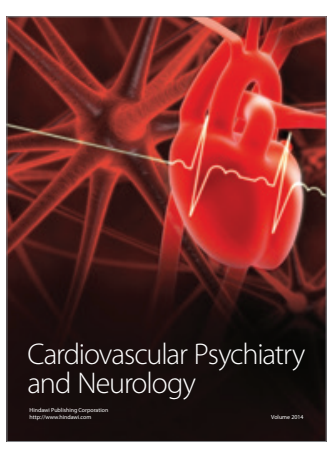

Parkinson's

Disease
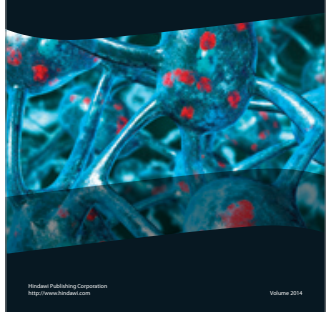